\begin{tabular}{|c|l|}
\hline Title & Synthesis and properties of SMA Ps 1-phospha 4 sil abicy clo[2.2.2]octane derivatives \\
\hline Author(s) & Ochida, A tsuko; Sawamura, Masaya \\
\hline Citation & ARKIV OC, 2006, 359-369 \\
\hline Issue Date & 2006-02-09 \\
\hline Doc URL & http:/hdl.handle.net/2115/17013 \\
\hline Type & article \\
\hline Note & Part (vii): Special Issue Plenary and Invited Lectures ICHC-20 \\
\hline File Information & ARKIV OC2006-pt.7.pdf \\
\hline
\end{tabular}

Instructions for use 


\title{
Synthesis and properties of SMAPs 1-phospha-4-silabicyclo[2.2.2]octane derivatives
}

\author{
Atsuko Ochida and Masaya Sawamura* \\ Division of Chemistry, Graduate School of Science, Hokkaido University, and \\ PRESTO, JST, Sapporo 060-0810, Japan \\ E-mail: sawamura@sci.hokudai.ac.jp
}

\begin{abstract}
Synthesis and properties of a new class of trialkylphosphine ligands SMAPs (1-phospha-4silabicyclo[2.2.2] octane derivatives, named after silicon-constrained monodentate alkylphosphine) with $\mathrm{Me}_{3} \mathrm{P}$-like steric demand around the phosphorus center are described. A new feature of this class of ligands is the presence of a site for functionalization at the backside of the $P$-lone pair, which is not the case for $\mathrm{Me}_{3} \mathrm{P}$. The SMAP ligands contain phosphorus and silicon atoms at each bridgehead of the bicyclo[2.2.2] octane framework. The molecular constraint of the bicyclic framework makes the steric demand around the phosphorus center as small as that of $\mathrm{Me}_{3} \mathrm{P}$ and projects the $P$-lone pair and the $S i$-substituent $(\mathrm{R})$ in diametrically opposite directions on the straight line defined by the two bridgehead atoms. SMAP derivatives bearing $S i$ substituents with varied electronic natures are obtainable by transforming the parent compound 4-phenyl-phospha-4-silabicyclo[2.2.2] octane (Ph-SMAP) through $\mathrm{Si}-\mathrm{Ph}$ bond cleavage, and they constitute a class of electronically tunable trialkylphosphines. DFT calculations indicated that the parent ligand $\mathrm{Ph}-\mathrm{SMAP}$ is similar to $\mathrm{Me}_{3} \mathrm{P}$ in donor power and that the tunable range of the donor power overlaps those of $(t-\mathrm{Bu})_{3} \mathrm{P}$ and $\mathrm{RAr}_{2} \mathrm{P}$ ( $\mathrm{R}$ : alkyl, $\operatorname{Ar}$ : aryl).
\end{abstract}

Keywords: Trialkylphosphines, 1-phospha-4-silabicyclo[2.2.2]octane, protodesilylation, silylcation, phosphine selenides, electrostatic potential minimum

\section{Contents}

1. Introduction

2. Synthesis of Ph-SMAP

3. X-ray crystal structure analysis of Ph-SMAP derivatives

4. Electronic properties of Ph-SMAP (DFT calculations)

5. Structure modification of SMAP at the bridgehead silicon 
6. Electronic substituent effect at the $\mathrm{Si}$-Ph group on $P$-donor power

7. Conclusion

8. References and Notes

\section{Introduction}

Trialkylphosphines have found wide application in coordination chemistry and organometallic chemistry as metal-coordinating ligands with strong $\sigma$-donating ability. One ligand with an extremely low steric demand is trimethylphosphine $\left(\mathrm{Me}_{3} \mathrm{P}\right)$. We have designed a new class of trialkylphosphine ligands 1 (SMAP, named after silicon-constrained monodentate alkylphosphine) with $\mathrm{Me}_{3} \mathrm{P}-$-like steric demand around the phosphorus center (Figure 1). ${ }^{1}$
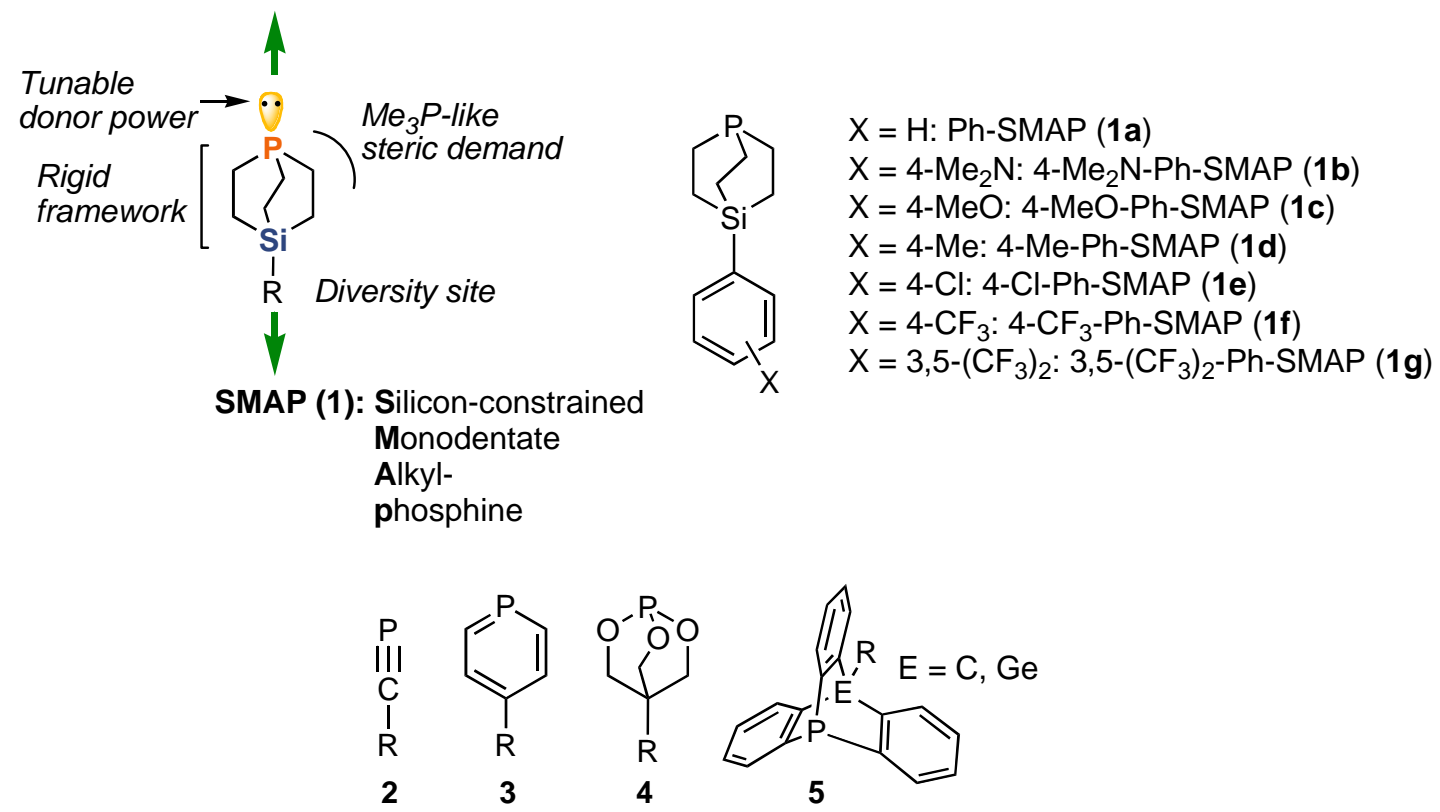

Figure 1. Structures of SMAP and related $P$-donor ligands.

A new feature of this class of ligands is the presence of a site for functionalization at the backside of the $P$-lone pair, which is not the case for $\mathrm{Me}_{3} \mathrm{P}$. The SMAP ligands 1 contain phosphorus and silicon atoms at each bridgehead of the bicyclo[2.2.2]octane framework. The molecular constraint of the bicyclic framework makes the steric demand around the phosphorus center as small as that of $\mathrm{Me}_{3} \mathrm{P}$ and projects the $P$-lone pair and the $S i$-substituent (R) in diametrically opposite directions on the straight line defined by the two bridgehead atoms (Figure 1). $P$-donor ligands that can be functionalized with such a directional constraint are rarely found and are limited to phosphaalkynes (2), ${ }^{2}$ phosphabenzenes (3), ${ }^{3}$ bicyclic phosphites 
(4) ${ }^{4}$ and phosphatriptycenes (5). ${ }^{5}$ To the best of our knowledge, no analogous trialkylphosphine ligand exists. ${ }^{6}$

SMAP derivatives (1a-1g, Figure 1) bearing $S i$ substituents with varied electronic natures are obtainable by transforming the parent compound $\mathrm{Ph}-\mathrm{SMAP}$ (1a) through $\mathrm{Si}-\mathrm{Ph}$ bond cleavage, and they constitute a class of electronically tunable trialkylphosphines. ${ }^{7}$ DFT calculations indicated that the parent ligand $\mathrm{Ph}$-SMAP is similar to $\mathrm{Me}_{3} \mathrm{P}$ in donor power and that the tunable range of the donor power overlaps those of $(t-\mathrm{Bu})_{3} \mathrm{P}$ and $\mathrm{RAr}_{2} \mathrm{P}$ (R: alkyl, Ar: aryl). This account describes the synthesis and properties of the SMAP derivatives.

\section{Synthesis of Ph-SMAP}

The synthesis of Ph-SMAP (1a) is illustrated in Scheme 1. Phenyltrivinylsilane (6) was converted into triol 7 through three-fold hydroboration with diisopinocampheylborane followed by $\mathrm{H}_{2} \mathrm{O}_{2} / \mathrm{NaOH}$ oxidation. ${ }^{8}$ The hydroboration proceeded with complete regioselectivity to give the primary alcohol against the electronic requirement of the silicon atom to induce the opposite selectivity. Mesylation of 7 and subsequent substitution with iodide anion afforded tris(2iodoethyl)phenylsilane (8). Then [5+1] annulation between the triiodide (8) and dilithium salt ${ }^{9}$ of $\mathrm{PhPH}_{2}-\mathrm{BH}_{3}$ produced the borane complex of monocyclic tertiary phosphine (9) as a mixture of cis- and trans-isomers (cis:trans $=c a$. 60:40). Upon heating with excess 1-octene in refluxing DME, the isomeric mixture of 9 was transformed into phosphonium salt 10. ${ }^{10,11}$ Subsequent reductive cleavage of the $\mathrm{P}-\mathrm{Ph}$ bond of $\mathbf{1 0}$ with lithium naphthalenide followed by reaction with sulfur afforded phosphine sulfide 11. Alternatively, addition of $\mathrm{BH}_{3} \cdot \mathrm{SMe}_{2}$ instead of $\mathrm{S}_{8}$ gave borane complex 12. Finally, reduction of the phosphine sulfide with $\mathrm{Si}_{2} \mathrm{Cl}_{6}{ }^{12}$ afforded white crystalline solid Ph-SMAP (1a): Mp 90.5-90.7 ${ }^{\circ} \mathrm{C}$ (in a sealed tube); sublimes at $40{ }^{\circ} \mathrm{C} / 0.04$ $\mathrm{mmHg} ;{ }^{31} \mathrm{P} \mathrm{NMR}\left(\mathrm{C}_{6} \mathrm{D}_{6}, 85 \% \mathrm{H}_{3} \mathrm{PO}_{4}\right) \delta-59.2\left(+3.0\right.$ relative to $\left.\mathrm{Me}_{3} \mathrm{P} / \mathrm{C}_{6} \mathrm{D}_{6}\right) .{ }^{13}$
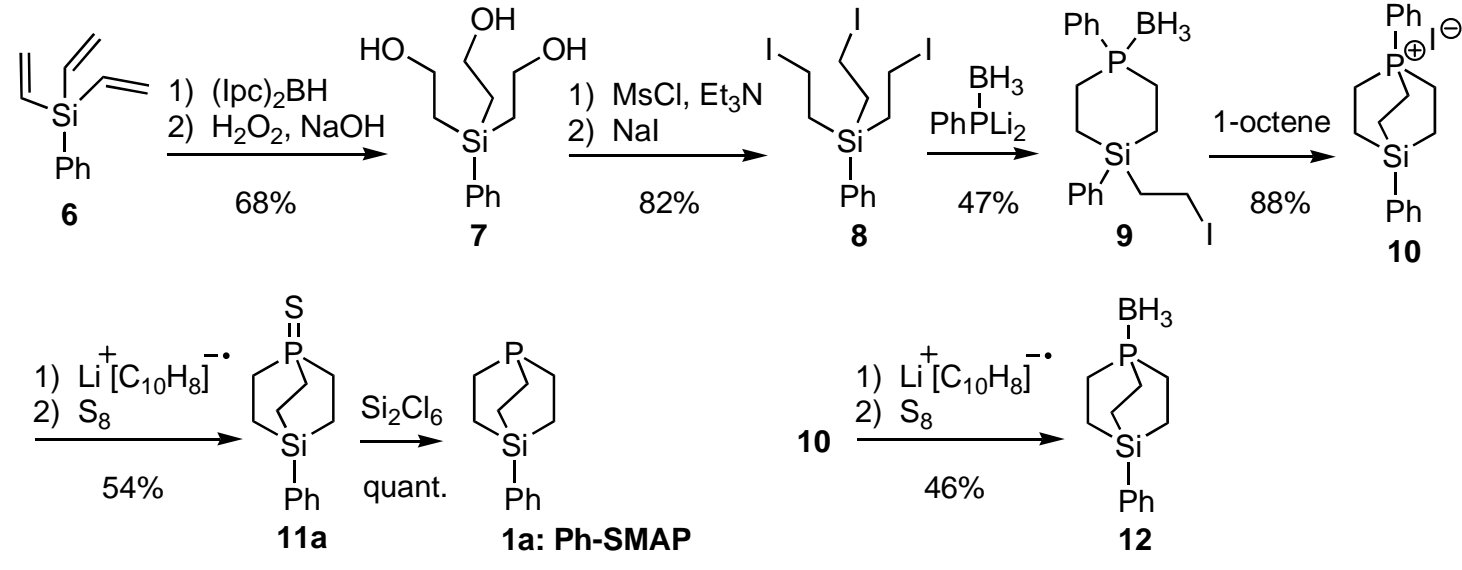

Scheme 1. Synthesis of Ph-SMAP. 
Solid Ph-SMAP is highly air-stable, with no detectable oxidation observed after exposure to air for several days. Moreover, being almost odorless, Ph-SMAP does not produce the noxious phosphine odor characteristic of volatile phosphines.

\section{X-ray crystal structure analysis of Ph-SMAP derivatives}

Single crystal X-ray diffraction analysis revealed a rod-like shape of Ph-SMAP (1a) and Ph$\mathrm{SMAP}_{-} \mathrm{BH}_{3}$ (12) (Figure 2). ${ }^{14,15}$ Analyses also showed that the bicyclic cage possesses some flexibility and twists toward chiral $C_{3}$-symmetric conformations. In free phosphine 1a, the values for the average $\mathrm{C}-\mathrm{P}-\mathrm{C}$ and $\mathrm{P}-\mathrm{C}-\mathrm{C}-\mathrm{Si}$ dihedral angles, and the $\mathrm{P}-\mathrm{Si}$ distance are $100.9^{\circ}, 15.5^{\circ}$ and $3.105 \AA$, respectively. In $\mathrm{BH}_{3}$ complex 12, the $\mathrm{P}$ atom bonds to the $\mathrm{B}$ atom with a distance of 1.922(2) $\AA .{ }^{16}$ The average $\mathrm{C}-\mathrm{P}-\mathrm{C}$ angle is enlarged to $104.2^{\circ}$. Such a slight enlargement of the angles around the $\mathrm{P}$ atom is typical for the metal coordination of a $P$-donor ligand. $\mathrm{The}^{\mathrm{BH}} \mathrm{H}_{3}$ coordination also causes shrinkage of the cage as indicated by enlargement of the $\mathrm{P}-\mathrm{C}-\mathrm{C}-\mathrm{Si}$ dihedral angles $\left(22.3^{\circ}\right.$, averaged) and shortening of the P-Si distance (3.031 $\AA$ ). Although the cage possesses some flexibility for twisting and stretching, almost no bending of the longest molecular axes was observed for both $\mathbf{1 a}$ and $\mathbf{1 2}$.
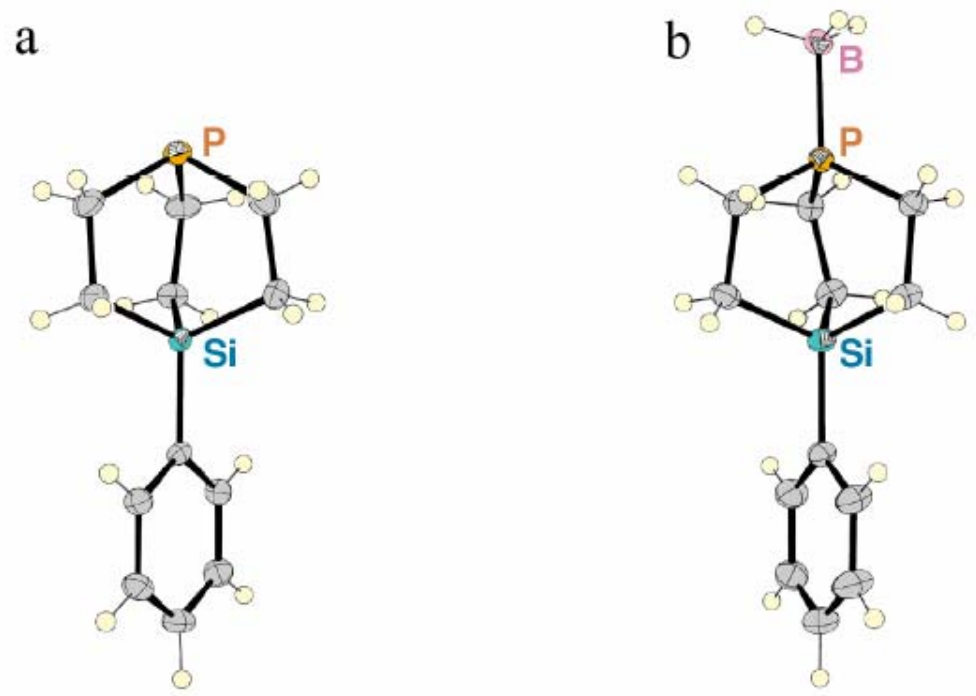

Figure 2. ORTEP drawings of the molecular structures of Ph-SMAP (1a, a) and Ph-SMAP-BH $(12, \mathrm{~b})$.

Figure 3 represents densely packed crystal structures of $\mathbf{1 a}$ and $\mathbf{1 2}$. The former consists of the two enantiomeric molecules $\left(P 2_{1} / n\right)$, while only a single enantiomer is involved in the latter (chiral space group: $\left.P 2_{1}\right)^{17}$ (This is a case of chiral crystallization of an achiral molecule with 
chiral conformations). The feature common to the crystal packing of $\mathbf{1 a}$ and $\mathbf{1 2}$ is the columnar stacking along the $a$ axis through van der Waals contacts between neighboring 1-phospha-4silabicyclo[2.2.2] octane cages. In both cases, the one-dimensional columns are further stacked along the longest molecular axis in a head-to-tail manner to form a sheet structure on the $a, c$ plane. In the case of 1a, the sheets are then stacked along the $b$ axis so that the cage and the aromatic ring are alternatively arranged to allow van der Waals contacts. In contrast, the sheet of 12 is stacked through $\mathrm{C}-\mathrm{H} \cdots \pi$ interactions between neighboring aromatic rings.
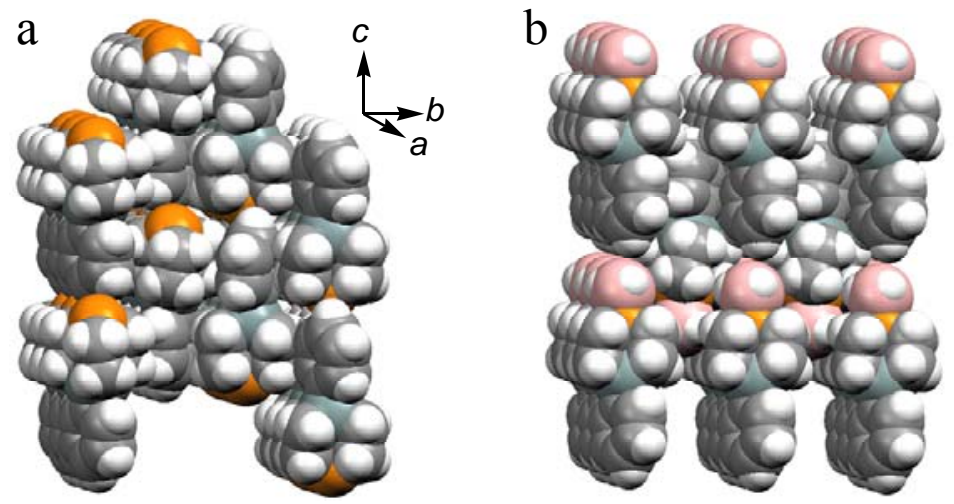

Figure 3.Crystal packing of Ph-SMAP (1a, a) and $\mathrm{Ph}-\mathrm{SMAP}_{-} \mathrm{BH}_{3}(\mathbf{1 2}, \mathrm{b})$.

\section{Electronic properties of Ph-SMAP (DFT calculations)}

DFT calculations [B3LYP/6-31G(d,p)] indicated that Ph-SMAP possesses an electron-donating ability as strong as that of $\mathrm{Me}_{3} \mathrm{P}$, and replacement of the Si atom of Ph-SMAP with a carbon atom drastically decreases the donor power. We optimized the geometry of Ph-SMAP (Figure 4a) and evaluated donor ability by the value of the molecular electrostatic potential minimum $V_{\text {min }}\left(\mathrm{kcal} \cdot \mathrm{mol}^{-1}\right.$ ) according to Koga's method. ${ }^{18}$ A larger negative $V_{\min }$ value corresponds to stronger electron-donating ability of a phosphine. For comparison, we also performed calculations for 4-phenyl-1-phosphabicyclo[2.2.2] octane (13, Figure 4b), an analog of Ph-SMAP that has a bridgehead carbon atom instead of the Si atom. ${ }^{19}$ As shown in Table 1 , the $V_{\min }(-$ $43.14 \mathrm{kcal} \cdot \mathrm{mol}^{-1}$ ) of $\mathrm{Ph}-\mathrm{SMAP}$ is much more negative than the value of monoaryldialkylphosphine $\mathrm{PhMe}_{2} \mathrm{P}$ and is in the range for trialkylphosphines, being between the values of $\mathrm{Me}_{3} \mathrm{P}$ and $\mathrm{Et}_{3} \mathrm{P}$. However, the $V_{\min }$ of $\mathbf{1 3}$ is less negative than that of $\mathrm{PhMe}_{2} \mathrm{P}$. The drastic decrease in donor ability upon placement of a carbon atom at the bridgehead may be due to the increase in $s$-character of the $P$-lone pair caused by the strain in the 1phosphabicyclo[2.2.2] octane cage. The strain is evident from the comparison of the $\mathrm{C}-\mathrm{P}-\mathrm{C}$ angles of the optimized structures; the avarage angle of $\mathbf{1 3}\left(96.2^{\circ}\right)$ is much smaller than that of Ph-SMAP $\left(99.7^{\circ}\right)$, and the latter is almost the same as the values of $\mathrm{Me}_{3} \mathrm{P}\left(99.4^{\circ}\right)$ and $\mathrm{Et}_{3} \mathrm{P}$ $\left(99.5^{\circ}\right)$. 

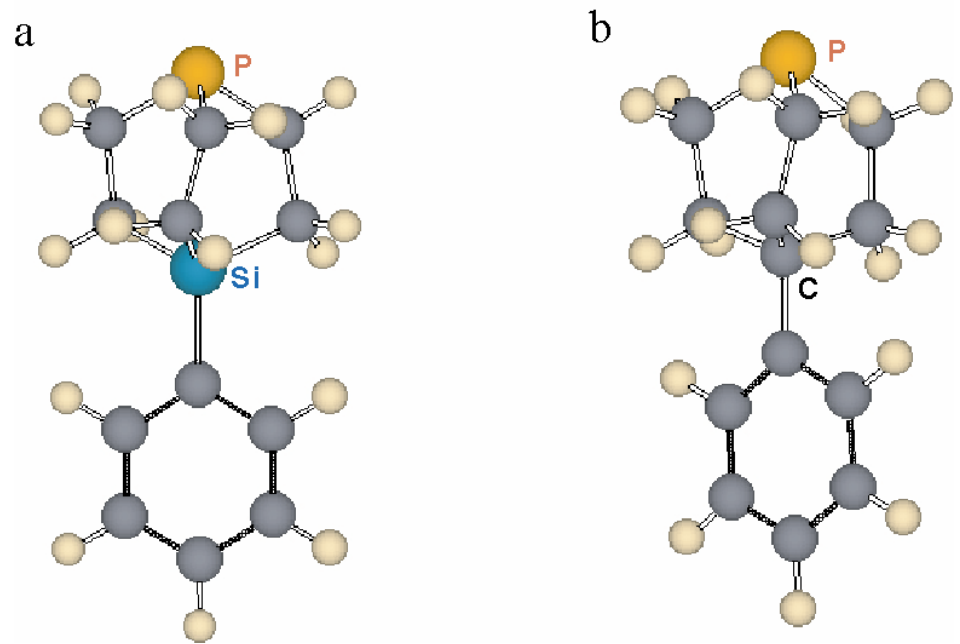

Figure 4. Optimized structures of Ph-SMAP (C-P-C angle 99.7 ${ }^{\circ}$, (a) and 13 (C-P-C angle $\left.96.2^{\circ}\right),(\mathrm{b})$.

Table 1. Results of DFT calculations for various tertiary phosphines

\begin{tabular}{cllc}
\hline Entry & Phosphine & $\begin{array}{l}V_{\text {min }} \\
\left(\mathrm{kcal} \cdot \mathrm{mol}^{-1}\right)\end{array}$ & $\begin{array}{l}\text { Average C-P-C } \\
\text { angle }\left({ }^{\circ}\right)^{a}\end{array}$ \\
\hline $1^{b}$ & $(t \text {-Bu })_{3} \mathrm{P}$ & -45.48 & 107.5 \\
$2^{b}$ & $(i-\mathrm{Pr})_{3} \mathrm{P}$ & -44.47 & 101.6 \\
$3^{b}$ & $\mathrm{Et}_{3} \mathrm{P}$ & -43.51 & 99.5 \\
4 & $\mathrm{Ph} \mathrm{SMAP}(\mathbf{1 a})$ & -43.14 & 99.7 \\
$5^{b}$ & $\mathrm{Me}_{3} \mathrm{P}$ & -43.02 & 99.4 \\
$6^{b}$ & $\mathrm{Me}_{2} \mathrm{PhP}$ & -40.41 & \\
7 & $\mathbf{1 3}$ & -39.06 & 96.2 \\
$8^{b}$ & $\mathrm{MePh}_{2} \mathrm{P}$ & -36.76 & \\
\hline
\end{tabular}

${ }^{a}$ Values of optimized structures. ${ }^{b}$ Data are taken from ref 18.

\section{Structure modification of SMAP at the bridgehead silicon}

SMAP derivatives with a substituted phenyl group on the bridgehead silicon were synthesized through a hydrosilane-type compound H-SMAP sulfide (14), a pivotal compound of diverse reactivity. The hydrosilane 3 was obtained as an air-stable crystalline material from Ph-SMAP sulfide (11a) through protodesilation with $\mathrm{TfOH}$ followed by reduction with $\mathrm{LiAlH}_{4}$ (Scheme 2). Note that the $\mathrm{Si}-\mathrm{Ph}$ bond in $\mathrm{Ph}-\mathrm{SMAP}$ sulfide was stable against protodesilation when compared to that in acyclic phenylsilane $\mathrm{Ph}-\mathrm{SiBu}_{3}$. While the latter was totally cleaved on treatment with 
$1.1 \mathrm{eq}$ of $\mathrm{TfOH}$ in $\mathrm{CH}_{2} \mathrm{Cl}_{2}$ at $0^{\circ} \mathrm{C}$ for $3 \mathrm{~h}$, the former needed $8 \mathrm{eq}$ of $\mathrm{TfOH}$ and a reaction time of $15 \mathrm{~h}$ at $25^{\circ} \mathrm{C}$ for $100 \%$ cleavage. The low reactivity of Ph-SMAP sulfide likely is due to instability of the leaving non-planar bridgehead silyl cation.

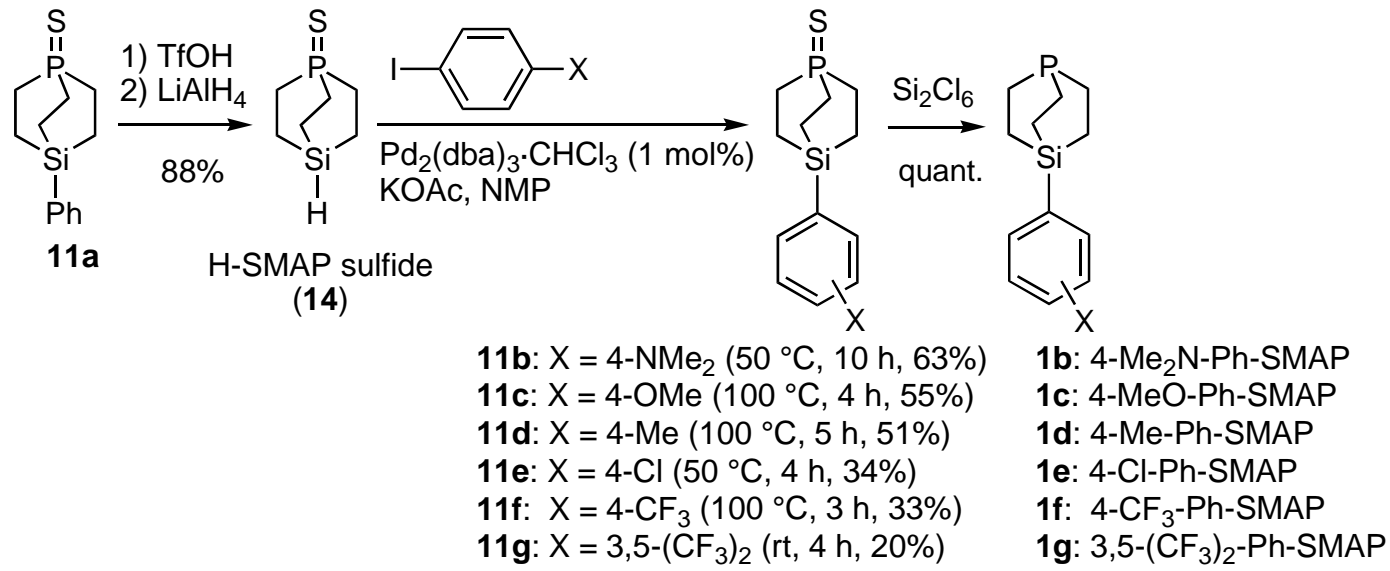

Scheme 2. Transformation of Ph-SMAP to other SMAP derivatives.

The palladium-catalyzed hydrosilane-iodoarene coupling developed by Masuda was applied to H-SMAP sulfide (14) to afford a series of SMAP sulfides (11b-g) ${ }^{20}$ The yield of the cross-coupling product depended on the iodoarenes and the reaction conditions. Generally the yield was improved (20\% 63\%) by slow addition of a solution of hydrosilane 3 into a solution of the catalyst and iodoarene. Reduction of the phosphine sulfides with $\mathrm{Si}_{2} \mathrm{Cl}_{6}$ afforded the corresponding phosphines (Ar-SMAPs, 1b-g). These phosphines are air-stable, crystalline, colorless solids that do not produce a noxious phosphine odor.

\section{Electronic substituent effect at the $S i$-Ph group on $P$-donor power}

DFT calculations $[\mathrm{B} 3 \mathrm{LYP} / 6-31 \mathrm{G}(\mathrm{d}, \mathrm{p})]$ indicated that the electronic character of the $P$-lone pair of the SMAP derivatives is strongly influenced by the distal Si substituents. ${ }^{21}$ We again used the molecular electrostatic potential minimum $V_{\min }(\mathrm{kcal} / \mathrm{mol})$ value associated with the phosphine lone pair region as a quantitative measure of donor power (Table 2). ${ }^{17}$ Calculations indicated that the donor powers of 4-MeO-Ph-SMAP (1c) and 4-Me-Ph-SMAP (1d) apparently were stronger than those of $\mathrm{Me}_{3} \mathrm{P}$ and $\mathrm{Ph}-\mathrm{SMAP}(\mathbf{1 a})$, and comparable with those of $\mathrm{Bu}_{3} \mathrm{P}$ and $\left(i\right.$-Pr) ${ }_{3} \mathrm{P}$ (entries 3-6). The para- $\mathrm{Me}_{2} \mathrm{~N}$ group exerts a much larger effect, increasing the donor ability of the aniline-type derivative 4-Me ${ }_{2} \mathrm{~N}$-Ph-SMAP $(\mathbf{1 b})$ even more than $(t-\mathrm{Bu})_{3} \mathrm{P}$, which is one of the $\sigma$ donor ligands possessing the strongest donor power (entries 1, 2). In contrast, substitution at the para-position with an electron-withdrawing group decreased donor power; the donating power of 4-Cl-Ph-SMAP (1e) and 4- $\mathrm{CF}_{3}-\mathrm{Ph}-\mathrm{SMAP}$ (1f) were comparable with monoaryldialkylphosphine $\mathrm{Me}_{2} \mathrm{PhP}$ (entries 9-11). Donor power of 3,5-( $\left.\mathrm{CF}_{3}\right)_{2}-\mathrm{Ph}-\mathrm{SMAP}(\mathbf{1 g})$ is as weak 
as that of $\mathrm{MePh}_{2} \mathrm{P}$ (entries 12,13). Figure 5 shows that the substitution effect at the para-position of Ph-SMAP on $V_{\min }$ is proportional to Hammett's substituent constant $\sigma$.

Table 2. $V_{\min }(\mathrm{kcal} / \mathrm{mol})$ for various phosphines and ${ }^{1} J\left({ }^{31} \mathrm{P},{ }^{77} \mathrm{Se}\right)(\mathrm{Hz})$ for phosphine selenides.

\begin{tabular}{|c|c|c|c|c|}
\hline Entry & SMAP & $\mathrm{R}_{3} \mathrm{P}$ & $\begin{array}{l}V_{\min } \\
(\mathrm{kcal} / \mathrm{mol})\end{array}$ & $\begin{array}{l}{ }^{1} J\left({ }^{31} \mathrm{P},{ }^{77} \mathrm{Se}\right) \\
(\mathrm{Hz})\end{array}$ \\
\hline 1 & 4-Me ${ }_{2} \mathrm{~N}-\mathrm{Ph}-\mathrm{SMAP}$ (1b) & & -46.58 & 729.3 \\
\hline $2^{a}$ & & $(t-\mathrm{Bu})_{3} \mathrm{P}$ & -45.48 & n.d. \\
\hline $3^{a}$ & & $(i-\operatorname{Pr})_{3} \mathrm{P}$ & -44.47 & n.d. \\
\hline 4 & 4-Me ${ }_{2} \mathrm{~N}-\mathrm{Ph}-\mathrm{SMAP}$ (1c) & & -44.30 & 734.2 \\
\hline 5 & 4-Me-Ph-SMAP (1d) & & -43.86 & 733.0 \\
\hline $6^{a}$ & & $\mathrm{Bu}_{3} \mathrm{P}$ & -43.71 & 717.1 \\
\hline 7 & Ph-SMAP (1a) & & -43.14 & 735.4 \\
\hline $8^{a}$ & & $\mathrm{Me}_{3} \mathrm{P}$ & -43.02 & 713.5 \\
\hline 9 & 4-Cl-Ph-SMAP (1e) & & -40.86 & 738.5 \\
\hline $10^{a}$ & & $\mathrm{Me}_{2} \mathrm{PhP}$ & -40.41 & n.d. \\
\hline 11 & 4- $\mathrm{CF}_{3}-\mathrm{Ph}-\mathrm{SMAP}$ (1f) & & -39.85 & 739.1 \\
\hline 12 & $3,5-\left(\mathrm{CF}_{3}\right)_{2}-\mathrm{Ph}-\mathrm{SMAP}(\mathbf{1 g})$ & & -37.77 & 742.2 \\
\hline $13^{a}$ & & $\mathrm{MePh}_{2} \mathrm{P}$ & -36.76 & n.d. \\
\hline
\end{tabular}

${ }^{a}$ Data taken from ref 18

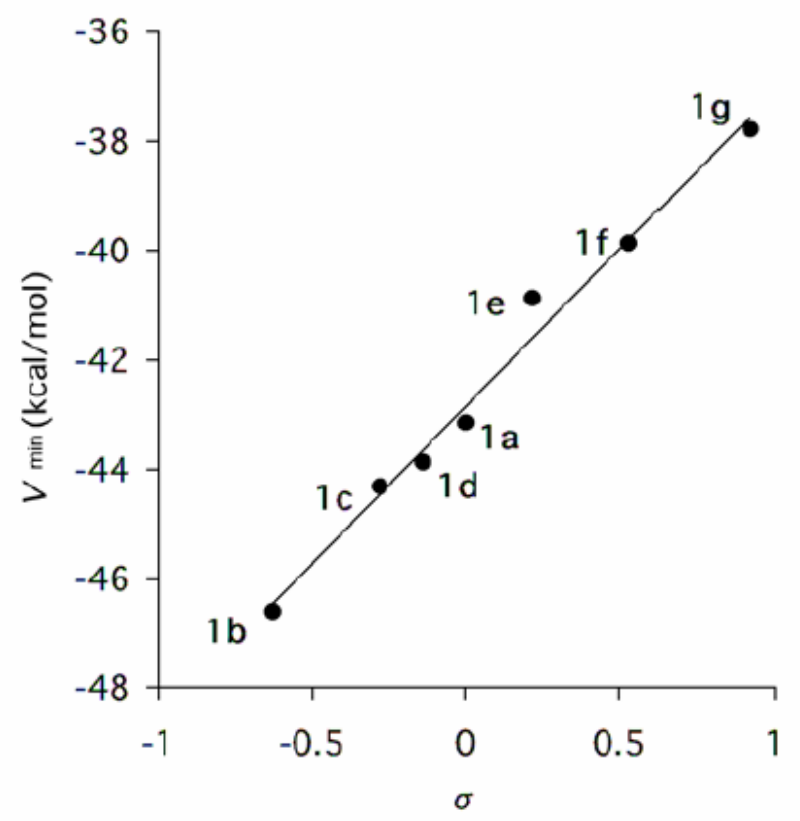

Figure 5. A plot of Vmin vs Hammett's substituent constants $\sigma$ 's for SMAP derivatives. 
The ${ }^{1} J\left({ }^{31} \mathrm{P},{ }^{77} \mathrm{Se}\right)$ measurements for phosphine selenides provided experimental evidence for the substituent effect at the bridgehead silicon atom on phosphine donor power. The selenides were prepared by heating a mixture of the phosphine and selenium in $\mathrm{C}_{6} \mathrm{D}_{6}$ in an NMR tube, and the ${ }^{1} J\left({ }^{31} \mathrm{P},{ }^{77} \mathrm{Se}\right)$ values were measured in situ. It is commonly accepted that the stronger the donor power is, the smaller the ${ }^{1} J\left({ }^{31} \mathrm{P},{ }^{77} \mathrm{Se}\right)$ value. ${ }^{22}$ Values for SMAP selenides (15a-g) and $\mathrm{Me}_{3} \mathrm{P}=\mathrm{Se}$ and $\mathrm{Bu}_{3} \mathrm{P}=$ Se are listed in Table 1 . The ${ }^{1} J\left({ }^{31} \mathrm{P},{ }^{77} \mathrm{Se}\right)$ values for the SMAP selenides increase by $12.9 \mathrm{~Hz}$ upon examination of the selenide (15b) possessing the strongest donating aryl-SMAP (1b) to that $(\mathbf{1 5 g})$ of the weakest donating one $(\mathbf{1 g})$. Figure 3 demonstrates that ${ }^{1} J\left({ }^{31} \mathrm{P},{ }^{77} \mathrm{Se}\right)$ values for SMAP selenides 15a-g show good linear correlation with the theoretical measures ( $V_{\min }$ 's). Figure 3 also shows that the values for $\mathrm{Me}_{3} \mathrm{P}=\mathrm{Se}$ and $\mathrm{Bu}_{3} \mathrm{P}=\mathrm{Se}$ are far below the correlation line for 15a-g. This drastic deviation is attributable to the change in steric environment around the $P$ center.

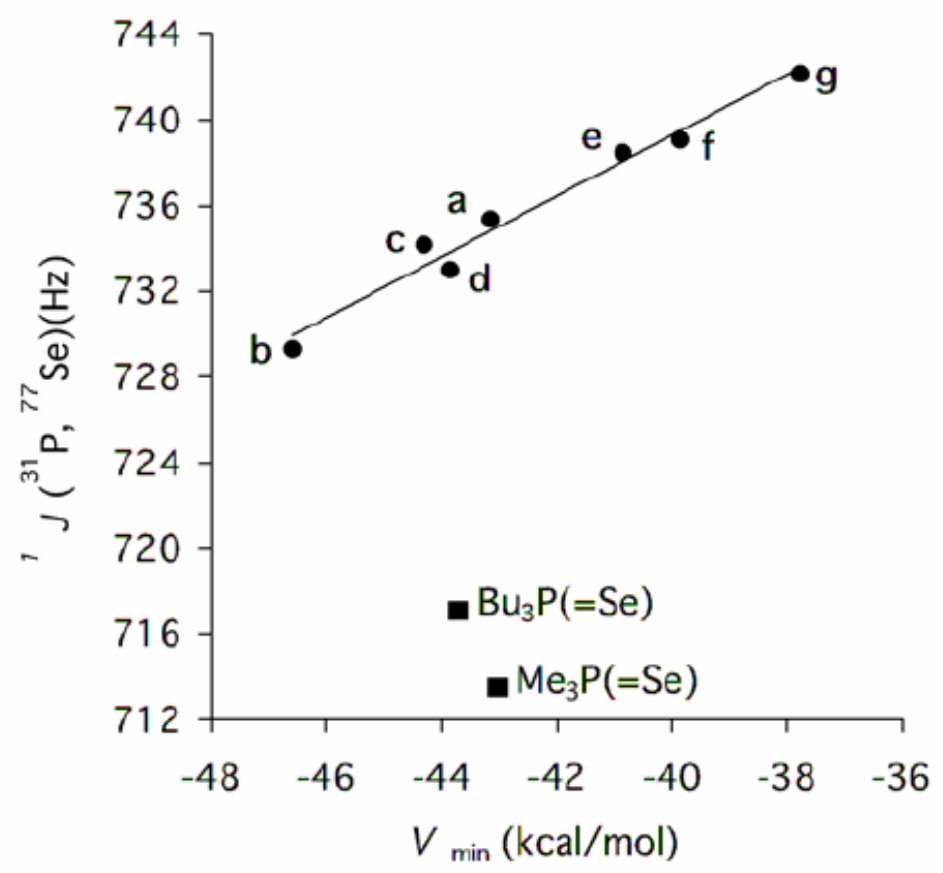

Figure 6. A plot of ${ }^{1} J\left({ }^{31} \mathrm{P},{ }^{77} \mathrm{Se}\right)$ vs $V_{\min }$ of the phosphine derivatives. The correlation line is associated with 1a-g/15a-g.

\section{Conclusions}

We presented a new class of trialkylphosphines SMAPs with steric and electronic features that guarantee its wide application as a robust ligand for transition metal coordination. SMAP derivatives with various $\mathrm{Si}$-substituents were synthesized by transforming Ph-SMAP through $\mathrm{Si}-$ $\mathrm{Ph}$ bond cleavage. The donor properties of the $P$-lone pair varied over a wide range depending 
upon the electronic nature of the $S i$ substituent, with retention of the steric demand around the phosphorus center. These characteristics should allow SMAPs to find diverse utility in mechanistic studies of organometallic reactions and in the development of efficient catalytic reactions. In addition, the molecular rigidity and flexibility of functionalization allows the preparation of a sophisticated series of SMAP ligands providing useful components for supramolecular architectures based on coordination chemistry.

\section{References and Notes}

1. Ochida, A.; Hara, K.; Ito, H; Sawamura, M. Org. Lett. 2003, 5, 2671.

2. (a) Markovskii, L. N.; Romanenko, V. D. Tetrahedron 1989, 45, 6019. (b) Nixon, J. F. Chem. Soc. Rev. 1995, 24, 319.

3. Le Floch, P.; Mathey, F. Coord. Chem. Rev. 1998, 178-180, 771.

4. Wadsworth, W. S. Jr.; Emmons, W.D. J. Am. Chem. Soc. 1962, 84, 610617.

5. (a) Jongsma, C.; De Kleijn, J. P.; Bickelhaupt, F. Tetrahedron 1974, 30, 3465. (b) Rot, N.; De Wijs, W.-J. A.; De Kanter, F. J. J.; Dam, M. A.; Bickelhaupt, F.; Lutz, M.; Spek, A. L. Main Group Met. Chem. 1999, 22, 519. (c) Agou, T.; Kobayashi, J.; Kawashima, T. Chem. Lett. 2004, 33, 1028.

6. For a diphosphine with a related structure, 1,4-diphosphabicyclo[2.2.2]octane, see: Hinton, R. C.; Mann, F. G. J. Chem. Soc. 1959, 2835.

7. Ochida, A.; Ito, S.; Miyahara, T.; Ito, H.; Sawamura, M. Chem. Lett. 2006, in press.

8. Brown, H. C.; Desai, M. C.; Jadhav, P. K. J. Org. Chem. 1987, 47, 5065.

9. Bourumeau, K.; Gaumont, A.-C.; Denis, J.-M. J. Organomet. Chem. 1997, 529, 205.

10. Uziel, J.; Riege, N.; Aka, B.; Figuière, P.; Jugé, S. Tetrahedron Lett. 1997, 38, 3405.

11. The high yield indicates that the both isomers were converted into the phosphonium salt $\mathbf{1 0}$.

12. (a) Zon, G.; Debruin, K.; Naumann, K.; Mislow, K. J. Am. Chem. Soc. 1969, 91, 7023. (b) Tang, W.; Zhang, X. Angew. Chem. Int. Ed. 2002, 41, 1612.

13. In the ${ }^{13} \mathrm{C}\left\{{ }^{1} \mathrm{H}\right\}$ NMR spectra of cage compounds 10, 11, 12 and 1a, the signals for the ipsocarbons of the $S i$-phenyl groups were observed as doublets with ${ }^{4} J_{\mathrm{C}-\mathrm{P}}$ coupling constants of $3.5,3.5,3.4$ and $4.5 \mathrm{~Hz}$, respectively. In contrast, no ${ }^{4} J_{\mathrm{C}-\mathrm{P}}$ coupling was observed for monocyclic compound 9. The long-range electronic interaction through the cage may suggest that electron-donating power of a SMAP ligand can be controlled by a Sisubstituent.

14. Crystal data for 1a: Monoclinic, $P 2_{1} / n$ (\#14), $a=6.3438(3) \AA, b=18.0866(5) \AA, c=$ $10.4720(6) \AA, \beta=100.732(1)^{\circ}, V=1180.52(9) \AA^{3}, Z=4$. Data collection: Rigaku RAXISRAPID Imaging Plate diffractometer, $T=-153^{\circ} \mathrm{C} .2 \theta_{\max }=54.9^{\circ}, R=0.041, R_{\mathrm{w}}=0.076, I$ $>1.5 \sigma(I), \mathrm{GOF}=1.96$. 
15. Crystal data for 12: Monoclinic, $P 2_{1}(\# 4), a=6.3632(3) \AA, b=7.6482(3) \AA, c=13.6844(7)$ $\AA, \beta=97.056(2)^{\circ}, V=660.93(5) \AA^{3}, Z=2$. Data collection: Rigaku RAXIS-RAPID Imaging Plate diffractometer, $T=-153{ }^{\circ} \mathrm{C}, 2 \theta_{\max }=54.9^{\circ}, R=0.028, R_{\mathrm{w}}=0.037, I>3 \sigma(I)$, $\mathrm{GOF}=1.26$.

16. The $\mathrm{P}-\mathrm{B}$ bond length of $\mathbf{1 2}$ (1.922(2) $\AA$ ) is apparently longer than that of $\mathrm{Me}_{3} \mathrm{P}-\mathrm{BH}_{3}(1.901$ $\AA)$ determined by microwave spectroscopy. See: Bryan, P. S.; Kuczkowski, R. L. Inorg. Chem. 1972, 11, 553-559. The reason of the elongation is not clear at present. Correlation between steric/electronic properties of phosphines and $\mathrm{P}-\mathrm{B}$ bond lengths are not clear in general. For a review, see: Brunel, J. M.; Faure, B.: Maffei, M. Coord. Chem. Rev. 1998, 178,665 .

17. This is a case of chiral crystallization of an achiral molecule with chiral conformations.

18. Suresh, C. H.; Koga, N. Inorg. Chem. 2002, 41, 1573.

19. The phosphine oxide form of 1-phosphabicyclo[2.2.2]octane was synthesized and its strain around the $P$ atom was discussed. But it has not been converted to the free phosphine. See: Wetzel, R. B.; Kenyon, G. L. J. Am. Chem. Soc. 1974, 96, 5189.

20. (a) M. Murata, K. Suzuki, S. Watanabe, Y. Masuda, J. Org. Chem. 1997, 62, 8569. (b) W. Gu, S. Liu, R. B. Silverman, Org. Lett. 2002, 4, 4171.

21. For MO analysis of the 1,4-diazabicyclo[2.2.2] octane system, see: E. Heilbronner, K. A. Muszkat, J. Am. Chem. Soc. 1970, 92, 3818.

22. D. W. Allen, B. F. Taylor, J. Chem. Soc. Dalton Trans. 1982, 51. 